\title{
Susceptibilidad a la licuación de suelos y sedimentos en el valle Ullum-Zonda (31'30' S-68²5' O), Precordillera, Andes Centrales, Argentina
}

\author{
Silvia Palacios ${ }^{1}$, Gabriela Lara $^{1}$, Laura Perucca ${ }^{1,2}$ \\ ${ }^{I}$ Gabinete de Neotectónica y Geomorfología, INGEO, FCEFyN-UNSJ, Avda. Ignacio de la Roza 590 Oeste, Complejo Universitario \\ Islas Malvinas, Departamento Rivadavia, Provincia de San Juan, Argentina. \\ silbea09@gmail.com,gabylara21@hotmail.com \\ 2 CONICET-UNSJ, Avda. Ignacio de la Roza 590 Oeste, Complejo Universitario Islas Malvinas, Departamento Rivadavia, Provincia \\ de San Juan, Argentina. \\ lperucca@unsj-cuim.edu.ar \\ * Autor para correspondencia: silbea09@gmail.com
}

RESUMEN. Los terremotos de 1894, 1944, 1952 y 1977 acontecidos en la provincia de San Juan en el centro-oeste de Argentina, produjeron numerosos procesos de licuación de suelos y depósitos sedimentarios, entre los que se destacan los ocurridos en el valle de Ullum-Zonda. Los registros históricos evidencian grietas, "volcanes de arena", cráteres y asentamientos diferenciales, los que ocasionaron importantes daños a las viviendas y al sector agroindustrial de la región. En este trabajo se estudió la susceptibilidad a la licuación de los suelos y depósitos sedimentarios del valle Ullum-Zonda mediante una metodología en la que se evaluaron y ponderaron los factores condicionantes, tales como profundidad del nivel freático, registros históricos de licuación, potenciales fuentes sismogénicas, origen y granulometría del suelo y depósito sedimentario, edad de los depósitos sedimentarios, entre otros. La influencia de los distintos factores en la evaluación de la susceptibilidad a la licuación se ponderó mediante un proceso iterativo de superposición de mapas. Una vez conseguida la combinación óptima se obtuvo un mapa final con la zonificación de la susceptibilidad a la licuación de suelos y depósitos sedimentarios del valle Ullum-Zonda. La zonificación lograda se relacionó con un índice de susceptibilidad (IS), catalogado cualitativamente como muy alta, alta, moderada y baja. La zona de muy alta susceptibilidad a la licuación se ubica preferentemente en el sector distal del abanico aluvial formado por el río San Juan en el valle de Ullum-Zonda, las zonas de alta a moderada susceptibilidad en el sector medio del abanico y las de moderada a baja susceptibilidad se corresponden con el sector proximal-medio del abanico. Los principales poblados del valle de Ullum-Zonda, es decir, la Villa Ibáñez (cabecera del departamento Ullum), al norte del río San Juan; la Villa Basilio Nievas (cabecera del departamento Zonda), al sur del río; el sector residencial Villa Tacú (situado al sur del embalse de Ullum) y los clubes náuticos (ubicados en la periferia noreste del embalse), se encuentran en las áreas de alta a muy alta susceptibilidad, en donde los principales factores condicionantes son la granulometría de los suelos y sedimentos y la profundidad del nivel freático.

Palabras clave: Terremotos, Licuación, Valle de Ullum-Zonda, San Juan.

\begin{abstract}
Susceptibility to soils and sediments liquefaction in the Ullum-Zonda valley (31 ${ }^{\circ} 30^{\prime} \mathrm{S}^{-68^{\circ}} \mathbf{2 5}$ ' W), Precordillera, Central Andes, Argentina. The earthquakes of 1894, 1944, 1952 and 1977 occurred in the province of San Juan in central-wesern Argentina caused numerous processes of soils and sediment liquefaction, including those in the Ullum-Zonda valley. Historical records showed cracks, sand volcanoes, craters and differential settlements, which caused significant damage to housing and the agro-industrial sector of the region. In this work, we carried out a study of the susceptibility to liquefaction of soils and sedimentary deposits in the Ullum-Zonda valley. This was conducted using a methodology in which conditioning factors such as depth of the water table, historical records of liquefaction, potential seismogenic sources, origin, age and grain size of the soils and sedimentary deposits, among others, were evaluated and weighted. An iterative process of overlapping maps weighted the influence of the different factors in
\end{abstract}


the assessment of susceptibility. Once the optimal combination was achieved, a final map with the zoning of soils and sediment susceptibility to liquefaction was obtained for the Ulum-Zonda Valley. The achieved zoning was related to a susceptibility index (SI), qualitatively classified as very high, high, moderate and low. The zone of very high susceptibility to liquefaction is located in the distal portion of the alluvial fan formed by the San Juan River in the Ullum-Zonda Valley, the areas of high to moderate susceptibility in the middle sector of the fan, and those of moderate to low susceptibility correspond to the proximal-middle sector of the fan. The main villages of the Ullum-Zonda valley, Ibáñez (head of the Ullum department) to the north of the San Juan River, Basilio Nievas (head of the Zonda department), to the south of the river, Tacú residential sector (located south of the Ullum dam) and the yacht clubs (located on the northeast periphery of the dam) are located in the areas of high to very high susceptibility, where the main conditioning factors are soil and sediments granulometry and the depth of the phreatic level.

Keywords: Earthquakes, Liquefaction, Ullum-Zonda Valley, San Juan.

\section{Introducción}

La licuación de suelos inducida por terremotos es uno de los principales factores de riesgo sísmico urbano. Las ondas sísmicas hacen que aumente la presión del fluido (agua) en los poros de los sedimentos, lo que reduce la tensión efectiva y, por lo tanto, disminuye su resistencia al corte. El exceso de agua en el suelo puede surgir en la superficie a través de grietas en la capa superior, arrastrar en el proceso arena licuificada y producir borbotones de arena, comúnmente llamados "volcanes de arena" (Rodríguez Pascua, 1997).

Los suelos más susceptibles a la licuación son aquellos formados durante el Holoceno, arenas y sedimentos de tamaños de partículas similares, en capas de hasta un metro de espesor y con un alto contenido de agua (saturadas). Tales depósitos por lo general se presentan en los lechos de ríos, playas, dunas y áreas donde se han acumulado arenas y sedimentos arrastrados por el viento y/o cursos de agua.

Los daños que pueden producir los procesos de licuación de suelos (PLS) van desde pequeños hundimientos y desplazamientos laterales (lateral spreadings) hasta deslizamientos de grandes masas de suelos. Además, pueden causar asentamientos $\mathrm{o}$ inclinaciones en fundaciones y estructuras de retención (Kramer y Stewart, 2004). Tinsley et al. (1985), Obermeier et al. (1990, 1993), Amicket al. (1990), Obermeier (1994), Youd et al. (2004), Palacios et al. (2017) y UCSB NEES (2018) coinciden en señalar que los factores que condicionan los procesos de licuación son los siguientes:

- Edad de los materiales sedimentarios: los suelos y depósitos sedimentarios jóvenes (menos de 3.000 años) presentan baja cohesión y por lo tanto son más susceptibles a la licuación que los suelos y depósitos más antiguos.

- Profundidad del nivel freático: la licuación disminuye notablemente con un nivel freático por debajo de los $3 \mathrm{~m}$, solo en condiciones particularmente inestables se genera licuación con el nivel freático ubicado por debajo de esta profundidad.

- Tamaño y forma del grano: el tamaño arena de medio a fino es vulnerable a la licuación. Las arenas uniformemente graduadas, de grano muy grueso a medio tienen mayor probabilidad de licuarse, mientras que las arenas limosas finas y las gravas lo hacen bajo cargas cíclicas más severas.

- Origen de los sedimentos: los sedimentos de grano fino depositados en ambientes lacustres y fluviales y ocasionalmente sedimentos marinos y costeros (playas) son más licuables. Los suelos depositados por procesos fluviales, litorales y eólicos se sedimentan fácilmente y sus granos tienen poca probabilidad de compactarse, de modo que se licuarán con facilidad.

- Potencia de los sedimentos: son necesarios espesores mínimos de $3 \mathrm{~m}$ de arenas o de alternancia de limos y arenas para facilitar el proceso de licuación.

- Amplitud de onda y duración de la vibración del terreno: la probabilidad de licuación aumenta con la magnitud (sismos con magnitudes mayores a 5) y la duración del sismo.

- Peso del recubrimiento y profundidad del suelo: en general, la licuación se da a profundidades menores de $9 \mathrm{~m}$ y ocasionalmente a más de $15 \mathrm{~m}$. El valle de Ullum-Zonda, situado en la Precordillera de los Andes Centrales de Argentina, centro-sur de la provincia de San Juan, es una depresión tectónica intermontana, elongada en 
sentido norte-sur, con una extensión aproximada de $30 \mathrm{~km}$ y un ancho de $14 \mathrm{~km}$ en su sector central (Fig. 1). Abarca un área aproximada de $290 \mathrm{~km}^{2} \mathrm{y}$ se ubica a una altura promedio de $800 \mathrm{~m}$ s.n.m. En el valle de Ullum-Zonda, la planicie de inundación del río San Juan se expande y forma un megaabanico aluvial, sobre el que se concentra principalmente la actividad agropecuaria y se emplazan pequeños poblados. El abanico aluvial ubicado en esta Unidad Morfoestructural Deprimida (Fig. 2) tiene una máxima extensión de $22 \mathrm{~km}$ en dirección meridional y $10 \mathrm{~km}$ en dirección este-oeste. Ha sido dividido en 4: un sector proximal-medio, uno medio, otro distal y la planicie de inundación actual del río San Juan. Esta unidad está limitada hacia el este y oeste por una Unidad Morfoestructural de Relieve Montañoso y por lomadas y depósitos de piedemonte indiferenciados de la Unidad Morfoestructural de Piedemonte Occidental y Oriental (Fig. 2).

El relleno cuaternario sedimentario en el valle de Ullum-Zonda está conformado por gravas, arenas, limos arenosos en los sectores más bajos ubicados al este de la depresión, y limos arcillosos donde se formaban lagunas o pantanos temporarios que se secaban estacionalmente. El acuífero, según lo indican las perforaciones, es libre, salvo en el sector noreste, donde, además de los limos superficiales, se registran intercalaciones limo arcillosas (Rocca, 1969). Aquí, por lo tanto, predominan condiciones de confinamiento o semiconfinamiento. Los datos

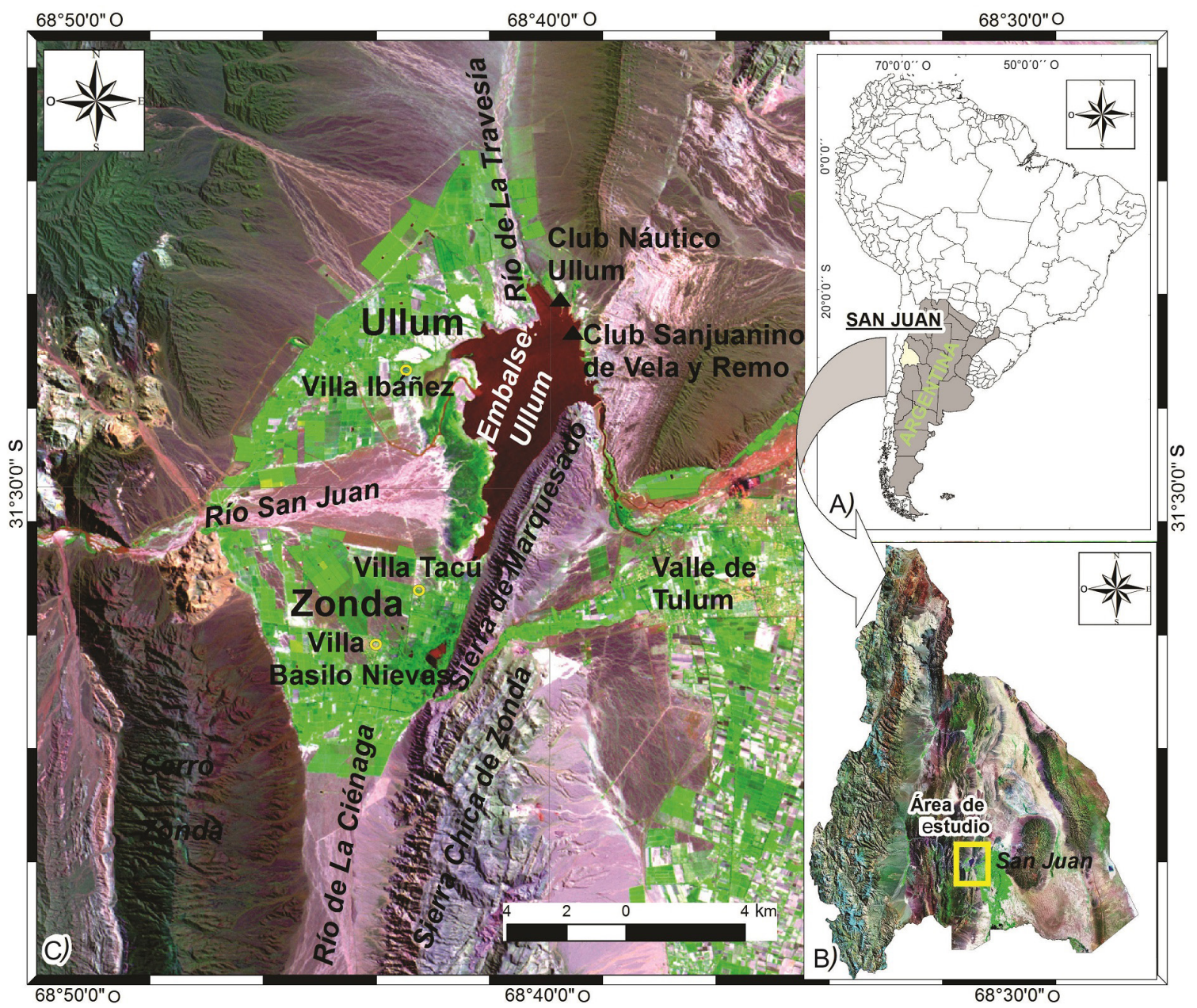

FIG. 1. Ubicación del área de estudio A. En Argentina y B. En San Juan, C. Imagen satelital del abanico aluvial del río San Juan en el valle Ullum-Zonda. 


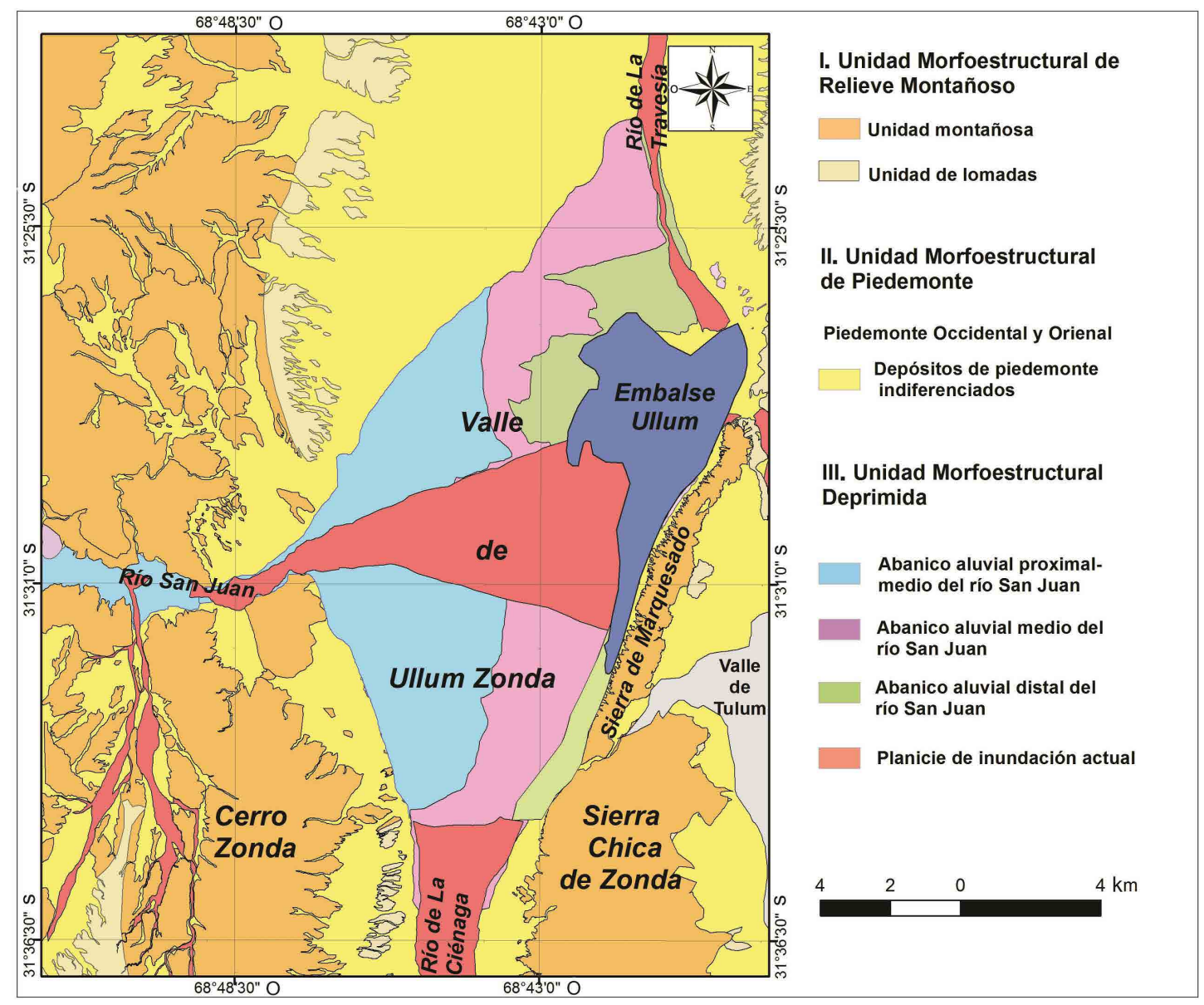

FIG. 2. Mapa de las principales unidades morfoestructurales del valle Ullum-Zonda y su entorno.

que aporta el Departamento de Hidráulica del Gobierno de la provincia de San Juan (DH, 2007²) indican un espesor saturado medio aproximado de $300 \mathrm{~m}$. Los acuíferos se alimentan por un proceso de recarga a través de la infiltración de agua aportada principalmente por el cauce del río San Juan y en menor medida por los ríos de La Travesía por el norte y de La Ciénaga por el sur, que de forma subterránea llegan a los mismos acuíferos $\left(\mathrm{DH}, 2007^{1}\right)$ con una reserva de $50.000 \mathrm{Hm}^{3}$ $\left(\mathrm{DH}, 2007^{1}\right)$. Actualmente la zona experimenta un periodo de sequía, con una duración de más de 10 años, con un marcado déficit hídrico y descenso de los niveles de agua subterránea. Sin embargo, cuando el río San Juan trae su caudal medio $\left(56 \mathrm{~m}^{3} / \mathrm{s}\right)$ los niveles de agua subterránea se recuperan en pocos meses y en aquellos años de abundante recarga, se produce la descarga del acuífero libre con formación de suelos anegados o salinizados (Liotta, 20112).

El objetivo de este estudio es estimar la susceptibilidad a la licuación de los suelos y sedimentos presentes en el valle Ullum-Zonda, en particular los que constituyen el abanico aluvial del río San Juan, por medio del análisis de los factores que condicionan este tipo de proceso.

DH. 2007. Relevamiento de las zonas de riego de la provincia de San Juan. Departamento de Hidráulica del Gobierno de la provincia de San Juan, Boletín Técnico Informativo (Inédito): $102 \mathrm{p}$.

2 Liotta, M. 2011. Los suelos del valle de Tulum y Ullum-Zonda. Área suelo, riego y drenaje. Estación Experimental Agropecuaria San Juan, Instituto Nacional de Tecnología Agropecuaria (INTA), Informe (Inédito): 18 p. San Juan. 


\section{Metodología}

Existen numerosos antecedentes históricos de licuación de suelos que ocurren repetidamente en los mismos lugares si las condiciones del sitio se mantienen constantes (Kramer y Stewart, 2004). Los procesos de licuación de suelos (PLS) en la provincia de San Juan se han repetido a lo largo de su historia sísmica, lo que demuestra que es una zona con una elevada tendencia a repetir el fenómeno. Los registros sísmicos históricos de la provincia de San Juan permiten deducir que los PLS podrían presentarse en eventos sísmicos futuros con igual o mayor magnitud que en eventos previos, razón que justifica un análisis detallado de los factores que influyen en su ocurrencia (Palacios, 2015; Palacios et al., 2017). Los factores considerados en este trabajo para evaluar la susceptibilidad de licuación de los suelos son los siguientes: 1) origen y tipo de depósito, 2) granulometría y profundidad de las capas licuables, 3) tipos de suelos y características texturales, 4) profundidad del nivel freático, 5) edad del depósito, 6) magnitud del sismo y distancia epicentral, 7) aceleración máxima instrumental, 8) licuación histórica. No se evaluaron los factores de densidad y peso del recubrimiento por no contar con datos suficientes para su análisis. De la ponderación de cada factor y de las imágenes satelitales se obtuvieron distintos mapas. Las imágenes fueron georreferenciadas en coordenadas geográficas (WGS84) a través de tecnología SIG. Además, se confeccionó una tabla evaluativa de susceptibilidad a la licuación, relacionando las características del sitio a un valor o clasificación que resume qué tan propicia es esa cualidad para que se genere el proceso de licuación. Los valores asignados van del 9 al 3, separados en cuatro rangos de números enteros impares, de más a menos susceptible, lo que facilitó la identificación y el manejo de la información (Tabla 1). La influencia o preponderancia de cada factor en la evaluación de la susceptibilidad de licuación se realizó mediante un proceso iterativo de superposición de los mapas zonificados, mediante softwares específicos tales como QGis y SAGA GIS.
TABLA 1. SUSCEPTIBILIDAD A LA LICUACIÓN ASIGNADA A LOS SUELOS Y SEDIMENTOS SEGÚN LOS ÍNDICES DE SUSCEPTIBILIDAD.

\begin{tabular}{cc}
\hline Índice & Susceptibilidad \\
\hline 9 & Muy alta \\
7 & Alta \\
5 & Moderada \\
3 & Baja \\
\hline
\end{tabular}

\section{Resultados}

\subsection{Análisis de los factores}

\subsubsection{Factor origen y tipo de depósito sedimentario/ suelos}

Para analizar este factor se tuvo en cuenta que tanto las arenas y gravas finas a muy finas (cuyos granos son redondeados y de tamaño uniforme) como los limos (groseros, sueltos y sin cohesión) son los más susceptibles de ser licuados. Por el contrario, el contenido de finos como las arcillas, genera en los granos del suelo suficiente adhesión, lo que limita su capacidad para generar licuación.

En la evaluación de este factor se tuvo en cuenta la profundidad y el espesor de las capas de arena (datos de 70 pozos aportados por el Departamento de Hidráulica del Gobierno de la provincia de San Juan, ver figura 3). Cabe destacar que, si bien desde el punto de vista geotécnico un suelo se clasifica de acuerdo con su integridad y capacidad portante en roca, suelo granular y fino, en este trabajo también se analizó el tipo de suelo con un criterio más edafológico, en función de su textura, según los datos aportados por el Instituto Nacional de Tecnología Agropecuaria (INTA, 1976³, ver figura 4). Ellos son poco profundos, esqueléticos y con muy escaso contenido de materia orgánica, incluso en ocasiones están ausentes, encontrándose solamente el material sedimentario depositado por el río.

Por otro lado, determinados tipos de suelos (e.g., franco-arenosos a arenosos) han sido los más afectados

\footnotetext{
INTA. 1976. Estudios de suelos y drenaje de los valles de Tulum, Ullum y Zonda. San Juan. Argentina. Estación Experimental Agropecuaria (Inédito): 1 (2): 210 p. San Juan.
} 


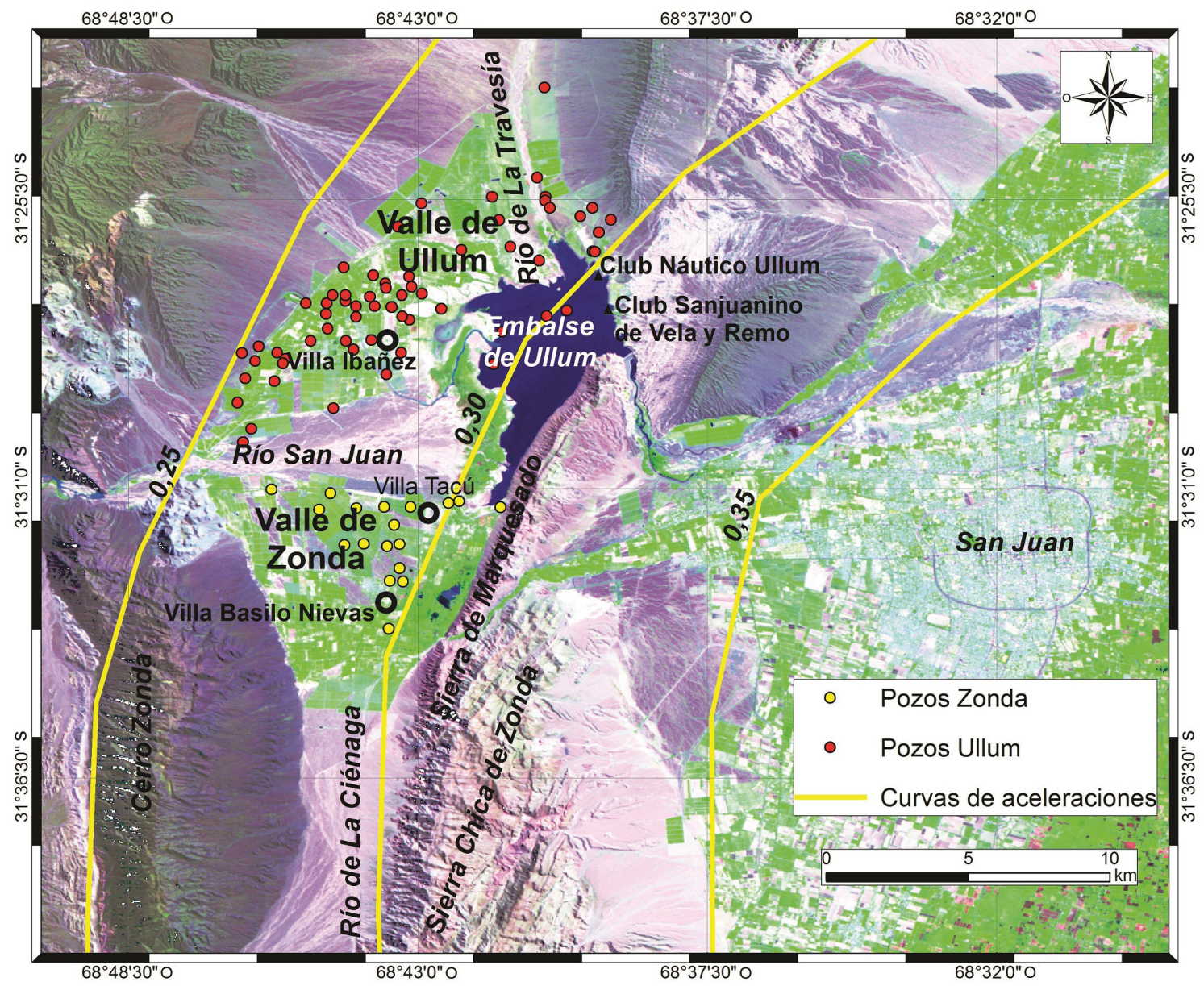

FIG. 3. Distribución de pozos de sondeo existentes en el abanico aluvial del río San Juan, valle Ullum-Zonda (DH, 19964). Curvas de aceleraciones máximas para el área de estudio basadas en los registros instrumentales del sismo Mw 7,4 de 1977 que afectó a la provincia de San Juan (Modificado de INPRES, 19825).

por procesos de licuación durante los terremotos históricos ocurridos en San Juan.

Analizando los mismos factores para todos los depósitos se les asignó distintos valores de susceptibilidad a la licuación (Tabla 2). Los datos granulométricos se obtuvieron a partir de la información de los pozos de sondeos realizados por el Departamento de Hidráulica del Gobierno de la provincia de San Juan (cuyas profundidades varían entre los 145 y $27 \mathrm{~m}$ ). Se asignó un valor 9 para una susceptibilidad muy alta, 7 para una alta, 5 para una media y 3 para una baja. De los 20 pozos excavados en el sector distal del abanico (Fig. 3), 5 presentan capas de arena fina a media con espesores entre 0,4 y $5 \mathrm{~m}$ hasta los $25 \mathrm{~m}$ de profundidad. El resto de los pozos tienen capas de grava, gravilla y arena, con espesores variables. Los pozos situados en el extremo sur del sector distal muestran capas de grava, gravilla y arena y otros pozos poseen capas de limos y arenas. Se clasificó con un valor 9 a los depósitos de arena del sector distal del abanico aluvial (Tabla 2). En el sector medio del abanico se analizó la información de 38 pozos, los que presentan capas de gravas, gravilla y arena con espesores variables;

\footnotetext{
DH. 1996. Registro de perforaciones privadas en el valle de Ullum-Zonda, San Juan, Argentina. Departamento de Hidráulica del Gobierno de la provincia de San Juan, Boletín Técnico Informativo (Inédito) 12: 9 p.

INPRES. 1982. Microzonificación sísmica del valle del Tulum, provincia San Juan. Instituto Nacional de Prevención Sísmica, Informe Técnico General (Inédito), 2: 50 p. San Juan.
} 


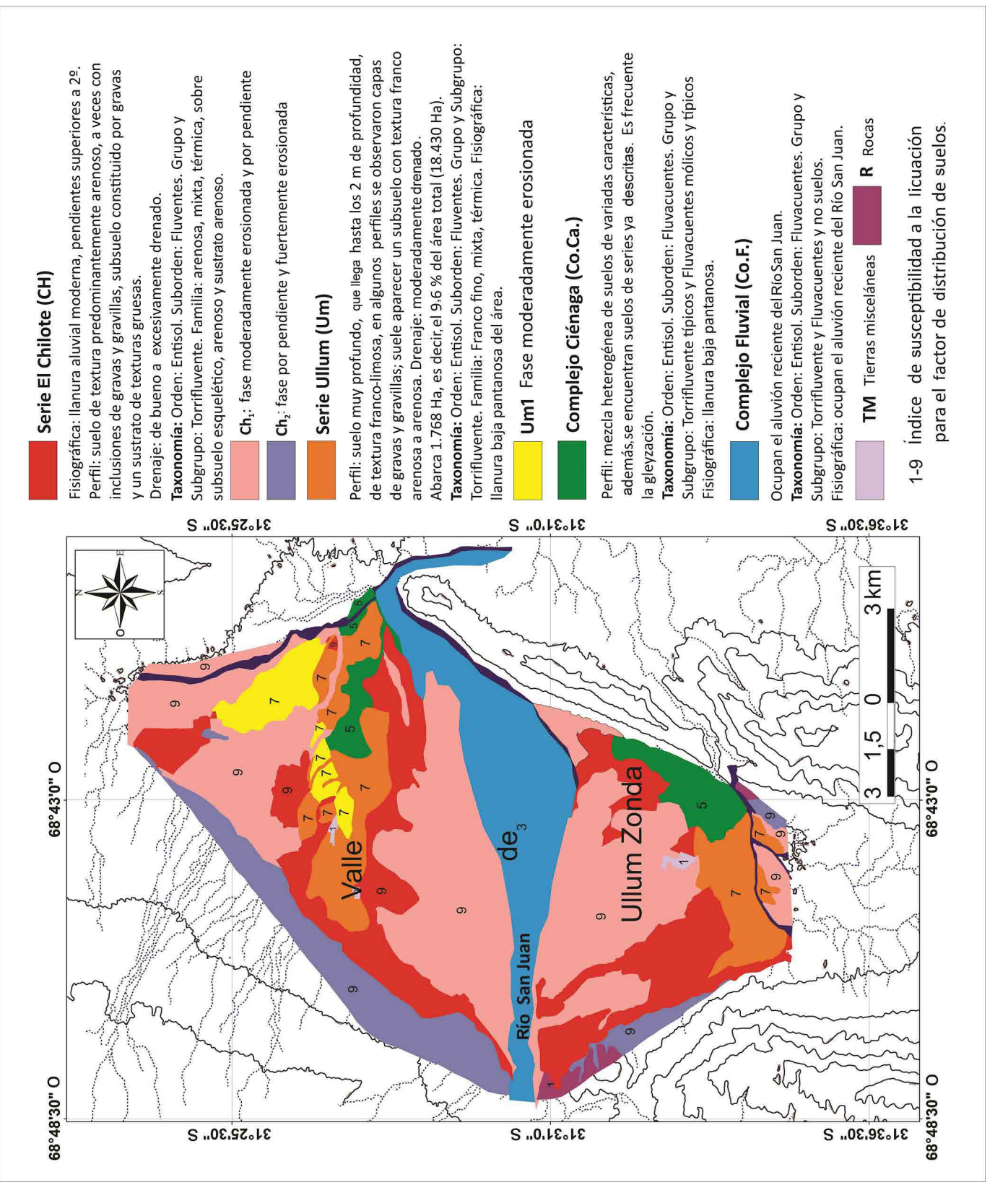




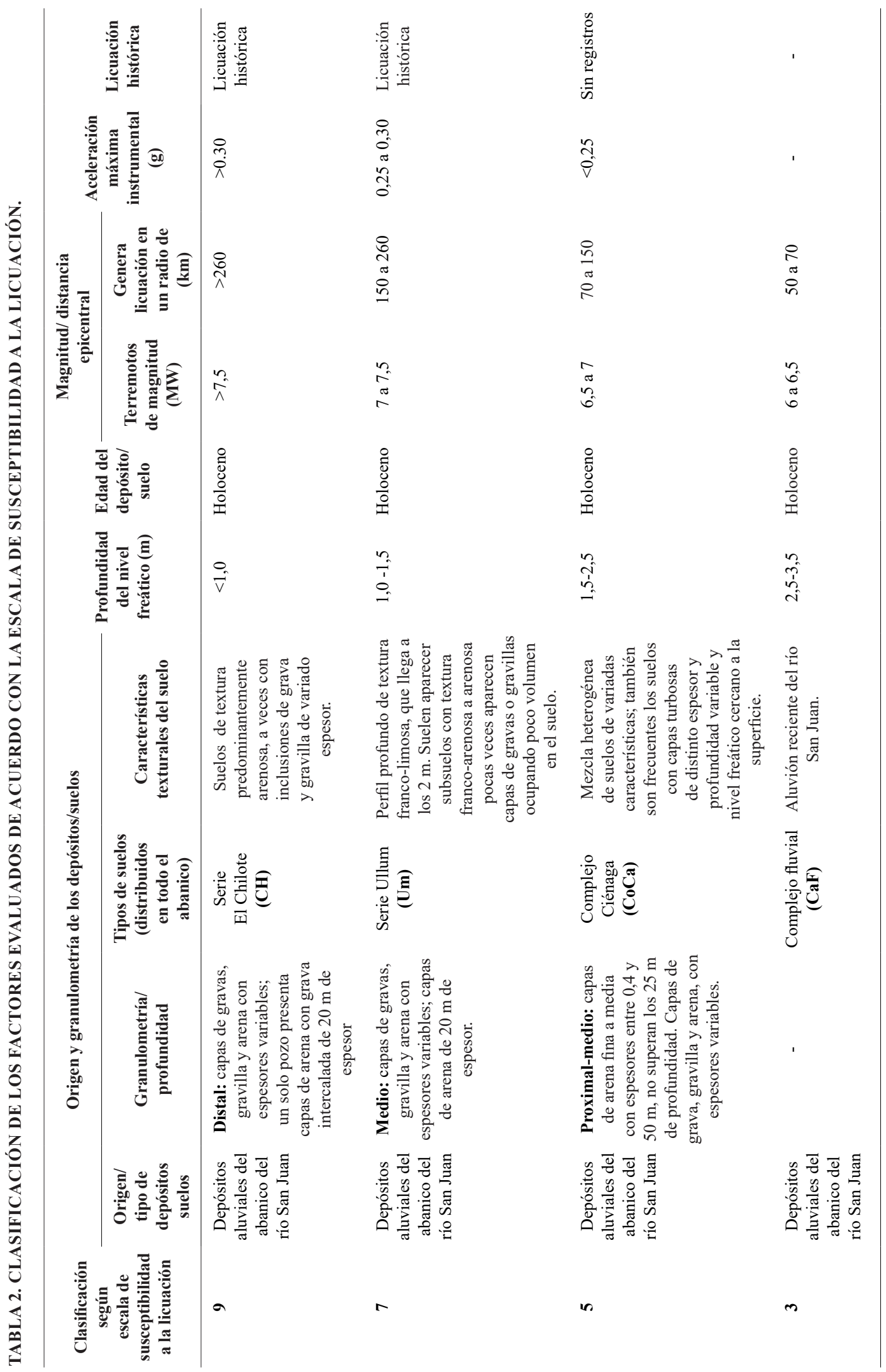


un solo pozo tiene capas de arena de $20 \mathrm{~m}$ de espesor. A partir de estos resultados, se asignó un valor 7 a este sector (Tabla 2).

En la porción proximal del abanico, 12 pozos tienen capas de gravas, gravilla y arena con espesores variables; un solo pozo presenta una capa de arena con grava de $20 \mathrm{~m}$ de espesor. De acuerdo con las características granulométricas de sus depósitos sedimentarios se asignó un valor 5 al sector proximal del abanico aluvial (Tabla 2).

Los suelos reconocidos en el área de estudio provienen de la alteración de material aluvial y aluvial-coluvial y son suelos jóvenes con escaso desarrollo de horizontes pedogenéticos, generados en un clima árido tipo desértico (Salcedo et al., 1976). En general, son suelos someros con clastos redondeados de rodados, gravas o gravillas desde la superficie o a distintas profundidades (Liotta, $2011^{2}$ ). Los principales parámetros para definir las series de suelos son la textura, la secuencia y la profundidad de las capas. También se admite para cada serie, variaciones de sus características principales, creándose fase y complejos de suelos (INTA, 19763). Las descripciones de los perfiles tipo se hacen considerando las capas desde la superficie hacia abajo y se las nombra como $\mathrm{A}=$ arcilloso, $\mathrm{L}=$ limoso, $\mathrm{F}=$ franco, $\mathrm{a}=$ arenoso, $\mathrm{r}=$ roca.

El perfil del suelo de la Serie Ullum (Um) es de textura predominantemente arenosa, a veces con inclusiones de gravas y gravillas, un subsuelo constituido por gravas y un sustrato de texturas gruesas (Fig. 4). El perfil del suelo de la Serie El Chilote (CH) puede alcanzar los $2 \mathrm{~m}$ de profundidad, es de textura franco-limosa, aunque en algunos perfiles se observan capas de gravas y gravillas. También hay un subsuelo con textura franco-arenosa a arenosa (Fig. 4). El perfil del suelo del Complejo Ciénaga (Co.Ca.) es una mezcla heterogénea de suelos de variadas características donde también se encuentran suelos de las series ya descritas (Fig. 4). El Complejo Fluvial (Co.F.) ocupa el aluvión reciente del río San Juan (Fig. 4).

Dadas las características texturales de los suelos, se le asignó un valor 9 a la Serie El Chilote $(\mathrm{CH})$ y a las fases $\left(\mathrm{CH}_{1}\right)$ y $\left(\mathrm{CH}_{2}\right)$; un valor 7 a la Serie Ullum (Um) y a su fase $\left(\mathrm{Um}_{1}\right)$; un valor 5 al Complejo Ciénaga (Co.Ca.) y un valor 3 al Complejo Fluvial (Co.F.). Finalmente, se le asignó un valor 1 a las tierras misceláneas $(\mathrm{TM})$ y a las rocas $(\mathrm{R})$ no diferenciadas (Fig. 4).

\subsubsection{Factor aceleración máxima instrumental}

No siempre un suelo arenoso es susceptible de ser licuado; para ello es necesario que el nivel de excitación sísmica (aceleración superficial y duración del sismo) sea el disparo del inicio de la licuación (Rodríguez Pascua, 1997). En cuanto a la magnitud (Mw) del sismo necesaria para producir licuación, esta debe ser igual o superior a 5,5 con aceleraciones en la superficie iguales o superiores a 0,2 g (González de Vallejo et al., 2009).

Para clasificar el potencial de licuación en función del factor aceleración máxima se analizó la información de los registros instrumentales (sismógrafos y acelerógrafos) obtenidos durante el terremoto de 1977 de magnitud Mw 7,4 con epicentro al sureste de la sierra de Pie de Palo (Fig. 5A), a $60 \mathrm{~km}$ al este de la ciudad de San Juan, aportados por el Instituto Nacional de Prevención Sísmica de la Provincia de San Juan (INPRES, 19825). Así, en la figura 3 se han representado las curvas de aceleración instrumental máxima más probable para un periodo de 50 años (INPRES, 19825).

El valle de Ullum-Zonda está limitado en su borde occidental por la curva de $0,25 \mathrm{~g}$ y en su sector oriental por la de $0,30 \mathrm{~g}$ (Fig. 3). Con estos datos se pudo asignar un valor 9 a los depósitos del sector distal del abanico, con aceleraciones mayores a $0,30 \mathrm{~g}$ y un valor 7 a los depósitos del sector medio del abanico, con aceleraciones comprendidas entre 0,25 y 0,30 g. A los depósitos del sector proximal del abanico se le asignó un valor 5 con aceleraciones máximas inferiores a $0,25 \mathrm{~g}$ (Tabla 2).

Las manifestaciones de licuación de los principales sismos históricos ocurridos en la región permitieron estimar sus respectivos radios de influencia, lo que se observa en la figura $5 \mathrm{~A}$ con color rojo, amarillo y verde, para los 200, 150 y $70 \mathrm{~km}$ respectivamente. Además, se ubicaron las principales fuentes sismogénicas en la provincia de San Juan y en el valle de UllumZonda (Fig. 5A, B) y los eventos sísmicos de $\mathrm{M} \geq 5$ con epicentros cercanos al área de estudio (Fig.5C).

\subsubsection{Factor profundidad del nivel freático}

El nivel estático del agua es un factor imprescindible al momento de evaluar la susceptibilidad a la licuación, ya que el proceso ocurre en un ambiente saturado. Para clasificar el potencial de licuación en función del factor profundidad del nivel freático se han analizado los planos de isobatas más superficiales, correspondiente a los meses más críticos del año 2014, 

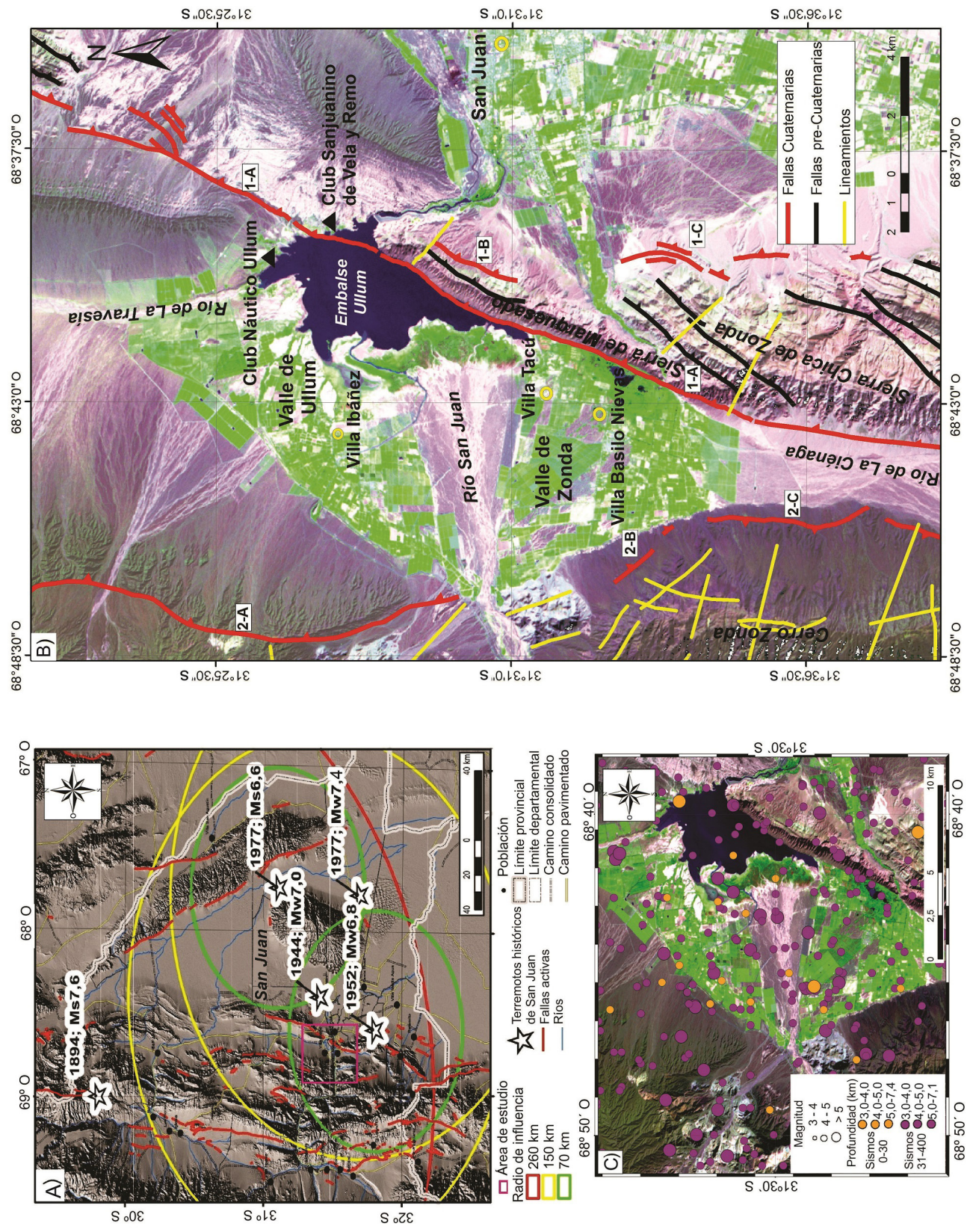

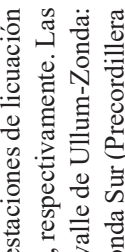

象这要

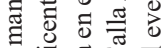

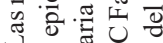

ส

.

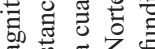

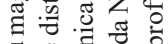

के

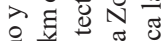

至

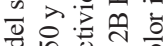

0 \%

空 命

능 $\stackrel{\text { ज }}{=}$

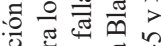

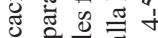

च

च छ

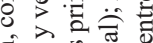

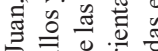

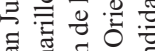

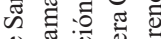

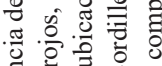

क ज

웅

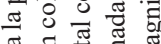

० : 글

范

逮 可

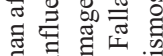

政

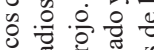

:

을 흘

फ 용

월

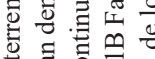

\% 융

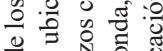

政

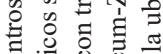

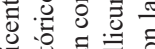

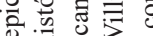

\%

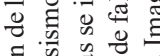

不

응 용

एँ

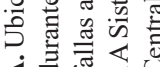

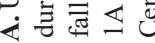

ن் 
cuando el nivel freático se encontraba más cerca de la superficie, esto es, de septiembre a noviembre (Fig. 6), según datos aportados por el Departamento de Hidráulica del Gobierno de la provincia de San Juan (DH, 2007'1). En el valle de Ullum-Zonda, el acuífero es libre, salvo en la porción noreste donde, además de los limos superficiales, se encuentran intercalaciones limo-arcillosas que favorecen las condiciones de confinamiento o semiconfinamiento. El espesor saturado medio es, por lo menos, de unos $300 \mathrm{~m}$. En el resto del abanico aluvial del río San Juan la permeabilidad es elevada y los caudales y

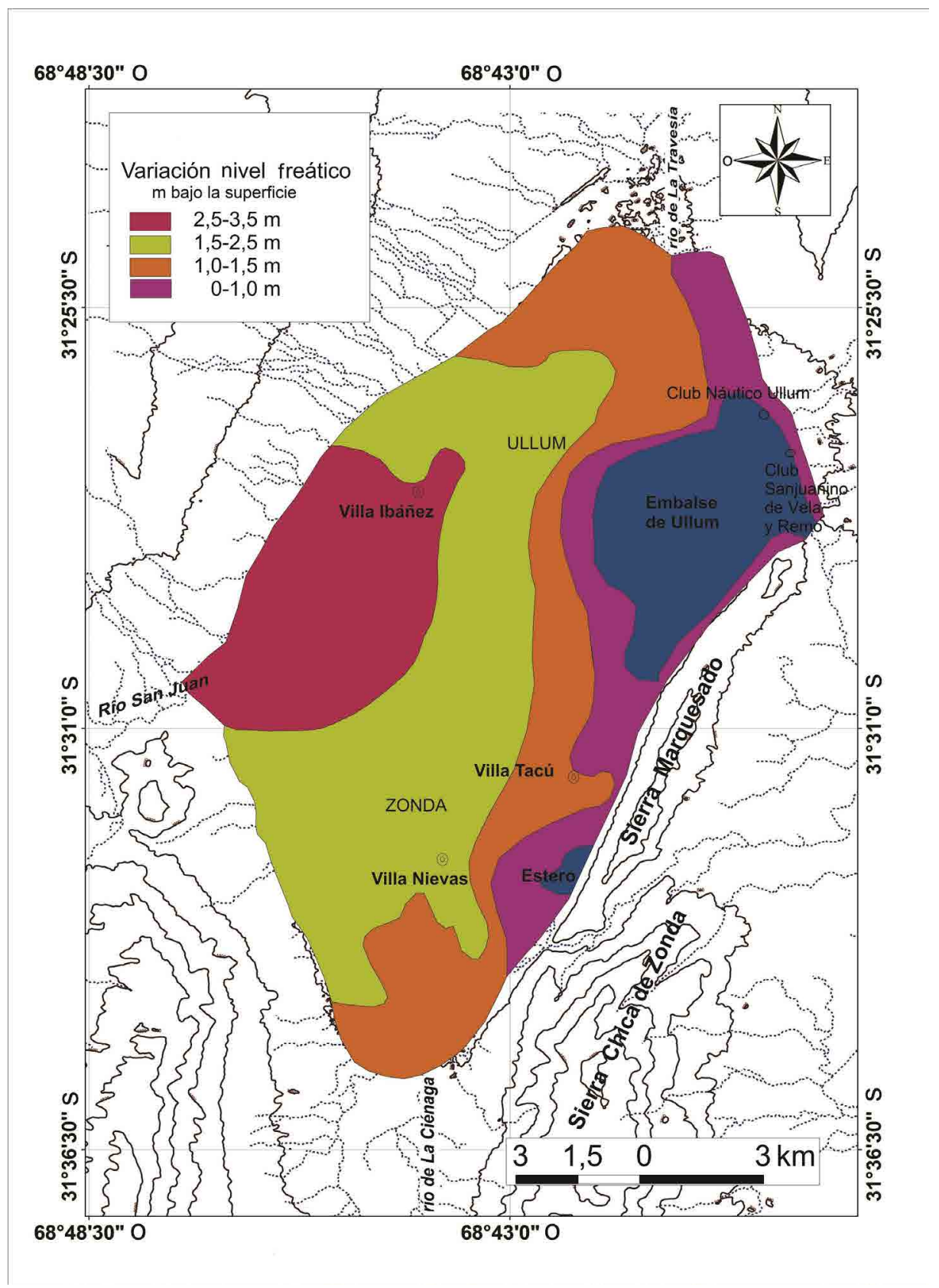

FIG.6. Mapa de variación de la posición del nivel freático en el área de estudio (Modificado de DH, 2007¹). 
rendimientos obtenidos en las perforaciones son altos, con un coeficiente de almacenamiento estimado no menor de 0,2 (Rocca, 1969). Los intervalos de profundidad del nivel freático considerados para clasificar el potencial de licuación se basaron en el estudio de Tinsley et al. (1985). Esto permitió asignarle un valor 9 a los niveles freáticos menores a $-1,0 \mathrm{~m}$, un valor 7 a las isobatas comprendidas entre $-1,0$ y $-1,5 \mathrm{~m}$, un valor 5 para los niveles freáticos comprendidos entre $-1,5$ y $-2,5 \mathrm{~m}$ y un valor 3 para los niveles entre $-2,5$ y $-3,5$ (Tablas 2,3 y 4).

\subsubsection{Factor edad de los depósitos sedimentarios}

La resistencia a la licuación se incrementa con la edad de los sedimentos. Los depósitos holocenos son los menos cohesivos, los sedimentos del Pleistoceno donde han actuado procesos de compactación y cementación natural son más resistentes, mientras que los depósitos del pre-Pleistoceno no son susceptibles de presentar licuación. La evaluación del potencial de licuación según el factor edad de los depósitos se corresponde con el valor 9, ya que todos los depósitos que conforman el abanico aluvial son atribuidos al Holoceno (Tablas 2 y 4 ).

\subsubsection{Factor licuación histórica}

Si bien no se encontraron en la zona imágenes que muestren los efectos de la licuación durante los terremotos históricos de San Juan (conos de arena, grietas y hundimientos en los suelos), Perucca et al. (2006) y Perucca y Moreiras (2006) señalaron que en las localidades de Zonda y Ullum se originaron hundimientos de áreas cultivadas y formación de grietas con escapes de agua y arena durante los terremotos de 1944 y 1952 (Tabla 2).

\subsubsection{Factor magnitud/distancia epicentral del evento sísmico}

Sobre la base de registros históricos se pudo establecer la relación entre la magnitud de un sismo con la distancia a la que se pueden generar procesos de licuación respecto de su epicentro. Se asignó un valor 9 a los sismos de magnitud $\mathrm{Mw}$ mayor a 7,4 que pueden generar licuación en un radio de influencia superior a $260 \mathrm{~km}$. Se fijó un valor 7 para sismos de magnitud entre 7,0 y 7,4, los que pueden generar licuación en un radio entre 150 a $260 \mathrm{~km}$. Se estipuló un valor 5 para los sismos de magnitud entre 6,5 a 7 para un radio de influencia entre 70 a $150 \mathrm{~km}$, y un valor 3 para sismos de magnitud entre 6 y 6,5 en un radio de influencia entre 50 a $70 \mathrm{~km}$. Finalmente, se asignó un valor 1 para los sismos menores a 6,0 en un radio de influencia menor a $50 \mathrm{~km}$ (Tablas 2 y 4). En la figura 5A se ubicaron los epicentros de los principales terremotos históricos destructivos, ocurridos en la provincia (Alvarado y Beck, 2006). Los registros históricos han mostrado que el terremoto de $1894(\mathrm{Ms}=7,6)$ generó estructuras de licuación a más de $150 \mathrm{~km}$ y el de $1977(\mathrm{Mw}=7,4)$ hasta $260 \mathrm{~km}$ del epicentro (INPRES, 1993; Perucca et al., 2006). Las manifestaciones de licuación de los sismos históricos se identificaron por medio de sus respectivos radios de influencia con colores rojo, amarillo y verde para los 200, 150 y $70 \mathrm{~km}$. Las fallas con actividad cuaternaria identificadas en la provincia de San Juan se indican con trazos continuos de color rojo, de acuerdo con la descripción efectuada por Perucca y Vargas (2014). Limitando por el oeste el valle de Ullum-Zonda se destacan las fallas que conforman el frente de corrimientos de la Precordillera Central (fallas Blanquitos, Zonda Norte

TABLA 3. SUSCEPTIBILIDAD A LA LICUACIÓN SEGÚN LA EDAD DE LOS DEPÓSITOS Y LA PROFUNDIDAD DEL NIVEL FREÁTICO (TOMADO DE TINSLEY ET $A L$., 1985).

\begin{tabular}{|c|c|c|c|c|}
\hline \multirow{2}{*}{ Unidad sedimentaria } & \multicolumn{4}{|c|}{ Profundidad del nivel freático $(\mathrm{m})$} \\
\hline & $0-3$ & 3-10 & $10-15$ & $>15$ \\
\hline \multicolumn{5}{|l|}{ Holoceno } \\
\hline Tardío & Alto a muy Alto & Moderado & Bajo & Muy bajo \\
\hline Temprano & Alto & Moderado & Bajo & Muy bajo \\
\hline \multicolumn{5}{|l|}{ Pleistoceno } \\
\hline Tardío & Bajo & Bajo & Muy bajo & Muy bajo \\
\hline Medio y Temprano & Muy bajo & Muy bajo & Muy bajo & Muy bajo \\
\hline Terciario y pre-Terciario & Muy bajo & Muy bajo & Muy bajo & Muy bajo \\
\hline
\end{tabular}




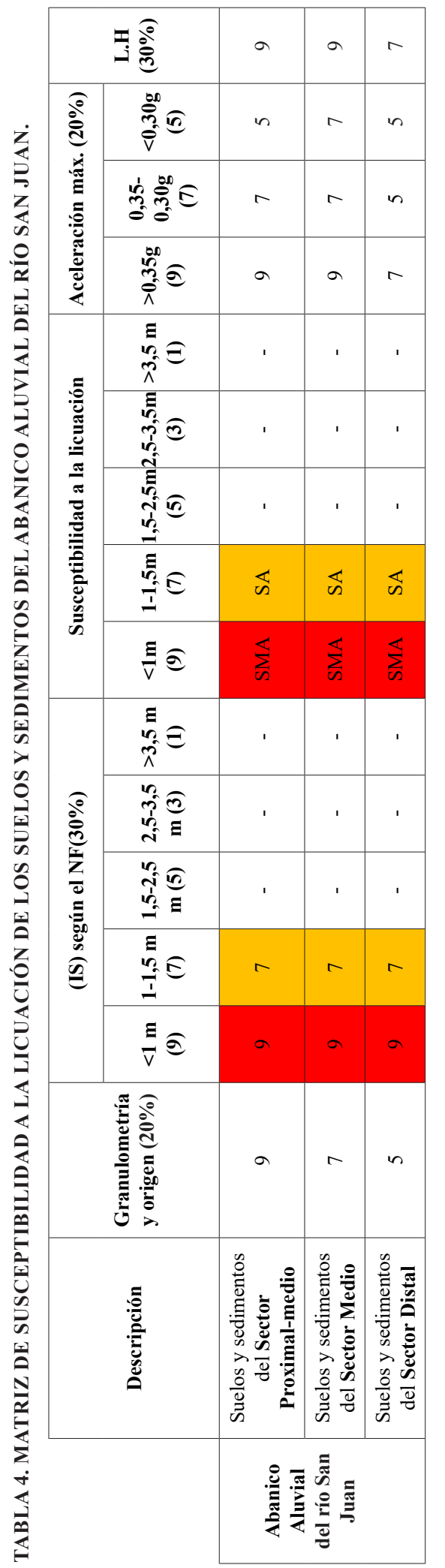

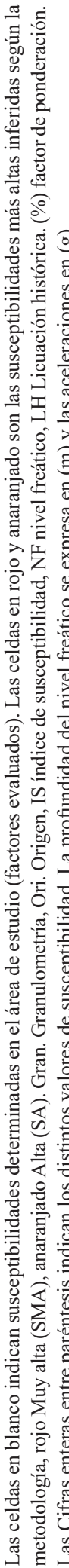

y Zonda Sur), cuyas evidencias sugieren actividad tectónica durante el Pleistoceno (Perucca et al., 2012; Perucca y Vargas, 2014) y por el este las estructuras cuaternarias de la Precordillera Oriental, tales como el Sistema de falla Villicum Zonda y las fallas Marquesado y Rinconada (Fig. 5B) todas ellas con evidencia de actividad tectónica holocena, con tasas de deslizamiento entre 0,5 y $0,8 \mathrm{~mm} /$ año e intervalos de recurrencia de $\sim 2,4 \mathrm{ka}$ (Siame et al., 2002). En la figura $5 \mathrm{C}$ se identifican con círculos amarillos los sismos instrumentales con profundidades entre $0 \mathrm{y}$ $30 \mathrm{~km}$ y con lila los eventos más profundos (USGS, 2018). Las magnitudes están indicadas de acuerdo con el diámetro de los círculos (cuanto mayor es el diámetro, mayor la magnitud).

La clasificación de los factores evaluados se muestra en la tabla 2 y la matriz de susceptibilidad en la tabla 4. Las celdas en blanco indican susceptibilidades observadas en el área de estudio (factores evaluados). Las celdas en rojo y anaranjado son las susceptibilidades inferidas según la metodología, (SMA) rojo-Muy alta y (SA) anaranjado-Alta.

\section{Ponderación de los mapas zonificados}

Para obtener el índice de susceptibilidad (IS) a la licuación, se ponderaron los mapas zonificados mediante un coeficiente que representa su porcentaje de influencia en el mapa de susceptibilidad final. Estos valores se obtuvieron luego de superponer los mapas vinculados a los distintos factores, hasta conseguir una relación que relacione las zonas consideradas potencialmente licuables con las zonas de alta susceptibilidad. Para definir los ponderadores se tuvo en cuenta la mayor o menor influencia de cada uno de los factores en el proceso de licuación, la relación entre ellos y las situaciones particulares de la zona de estudio. Se le asignó el mayor porcentaje a los factores profundidad del nivel freático (sin agua no es posible la licuación) y licuación histórica, ya que si bien no se encontraron archivos fotográficos con evidencia de licuación específicamente en la zona de estudio, existen antecedentes que señalan su ocurrencia durante los sismos de 1944 y 1952 (Harrington, 1944; INPRES, 1993; Perucca et al., 2006; Perucca y Moreiras, 2006) sumados a los numerosos relatos que aportaron los testigos presenciales del sismo de 1977 (INPRES, 1993).

Los valores de los coeficientes de la ecuación (1) que mejor modelan la susceptibilidad a la licuación de 
la zona son $\mathrm{a}=20 \% ; \mathrm{b}=20 \% ; \mathrm{c}=30 \% ; \mathrm{d}=30 \%$ (Palacios, 2015; Palacios et al., 2017). El resultado de esta ponderación se denomina índice de susceptibilidad (IS), que se expresa en la ecuación (1) como:

$\mathrm{IS}=\mathrm{a} \times \mathrm{GO}+\mathrm{b} \times \mathrm{AM}+\mathrm{c} \times \mathrm{NF}+\mathrm{d} \mathrm{LH}$

$\mathrm{GO}=$ granulometría y origen del depósito

$\mathrm{AM}=$ aceleración máxima

$\mathrm{NF}=$ profundidad del nivel freático

LH=Licuación histórica

$\mathrm{a}, \mathrm{b}, \mathrm{c}, \mathrm{d}=$ coeficientes

El valor del índice de susceptibilidad (IS) fue redondeado al entero más cercano e interpretado cualitativamente, resultando: $I S=9-8$ (SMA); IS=7-6 (SA); IS=5-4 (SM); IS=3-1 (SB), valores que indican susceptibilidades Muy Altas, Altas, Moderadas y Bajas respectivamente (Tabla 4; Fig. 7).

Mediante el uso de un sistema de información geográfica (SIG) se trabajó con una superposición de capas (mapas de nivel freático, de suelos considerando sus granulometrías, curvas de aceleraciones, etc.) y se confeccionó un mapa final, donde se destacan los distintos grados de susceptibilidad a la licuación: con color rojo la susceptibilidad muy alta (SMA), anaranjado la alta (SA), amarillo la moderada (SM) y verde la baja (SB), según se aprecia en la figura 7.

\section{Discusión}

\subsection{Consideraciones respecto a los factores}

La revisión de documentos históricos es la primera fuente para identificar las zonas susceptibles a priori de presentar licuación inducida por un sismo, por lo que el factor licuación histórica se considera íntimamente relacionada con todos los demás factores. Tanto en los relatos de testigos presenciales del terremoto de 1977 como en trabajos previos referidos a los ocurridos en 1944 y 1952, se describen efectos de licuación de suelos en la región de estudio (Harrington, 1944; INPRES, 1993; Perucca et al., 2006; Perucca y Moreiras, 2006).

Con respecto al análisis de las aguas subterráneas, no existe una relación directa entre la profundidad

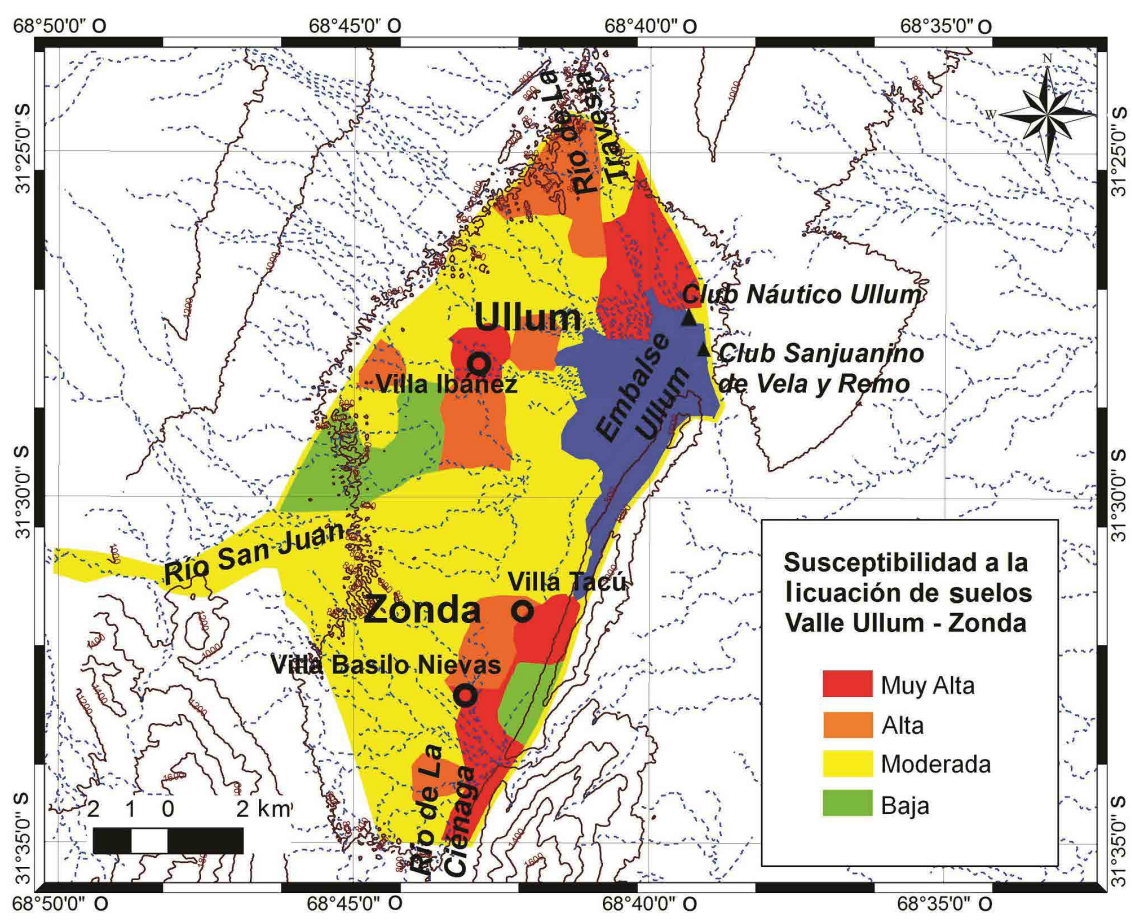

FIG.7. Mapa de susceptibilidad a licuación de los suelos y sedimentos del valle Ullum-Zonda. Los colores rojo, anaranjado, amarillo y verde representan susceptibilidades muy alta, alta, moderada y baja, respectivamente. 
del nivel freático (o estático) con el resto de los factores. No obstante, la granulometría y la densidad del depósito pueden condicionar los cambios en la posición del nivel freático en periodos cortos, ya sea por una perturbación en la profundidad del agua subterránea (e.g., riego, bombeo de aguas) o por cambios estacionales. Sin embargo, el nivel freático no se recupera inmediatamente, necesitando un cierto tiempo para recobrar su condición original. Esto se debe a que el escurrimiento está controlado por la permeabilidad del subsuelo, elemento que en parte depende de la porosidad. El factor granulometría del suelo se unificó con el tipo de suelo/textura debido a que el primero es el que realmente influye en la susceptibilidad final, según lo observado tanto en los registros históricos como en el área del valle del Tulum (Palacios, 2015; Palacios et al., 2017). Con respecto a la aceleración máxima, no existe relación directa entre la amplitud de vibración y los demás factores, por lo que fue considerada independiente del resto. Con respecto a la sectorización obtenida para el abanico aluvial del río San Juan en el valle de Ullum-Zonda, debe destacarse que el contacto establecido entre los distintos sectores de los depósitos del abanico aluvial del río San Juan (próximo-medio, medio y distal) es estimativo, ya que por un lado no se tiene información granulométrica suficiente que permita establecer el límite preciso entre los distintos sectores y por otro, los contactos no son netos, sino transicionales con variaciones locales que no fueron consideradas por la escala de trabajo utilizada.

\subsection{Consideraciones respecto a las ponderaciones}

El grado de susceptibilidad a la licuación obtenido a partir de los índices de susceptibilidad (IS) depende en gran medida del porcentaje de influencia de cada factor en el proceso. Se recomienda que tanto la ponderación del factor nivel freático como la licuación histórica nunca sea inferior al 30\%, debido a que, si el nivel freático es profundo, no se producirá licuación independientemente de la granulometría del depósito, proximidad de fallas activas o magnitud del sismo. Además, la evidencia de licuación durante los terremotos históricos indica que ésta se repetirá en los eventos futuros si los depósitos se encuentran saturados. Por lo tanto, ambos factores son imprescindibles para evaluar la susceptibilidad a la licuación. Sin embargo, para estudios más detallados se sugiere incluir ensayos de mecánica de suelos, no aplicados en esta etapa del trabajo.

\subsection{Evaluación del peligro potencial de licuación}

La metodología empleada buscó dar un sustento teórico basado principalmente en pautas generales de comportamiento de los factores que influyen en el potencial de licuación.

A partir del estudio de la incidencia ejercida por diferentes factores tales como la presencia de materiales arenosos, proximidad de fuentes sismogénicas potenciales, magnitudes de los sismos históricos e instrumentales, profundidad del nivel freático y reportes históricos de licuación en el valle de Ullum-Zonda, entre otros, se identificaron las zonas propensas a licuar y aquellas donde la susceptibilidad es baja o nula. El objetivo final fue obtener un mapa de zonificación del peligro, el que constituye la expresión más sintética de los resultados de esta investigación. La zona de muy alta susceptibilidad a la licuación se ubica en el sector distal del abanico, las áreas de altas a moderada susceptibilidad en el sector medio y las de moderada a baja susceptibilidad se corresponden con el sector proximal-medio del abanico. La zona de muy alta susceptibilidad identificada representa un nivel general del peligro potencial de licuación, condicionado principalmente a que los suelos arenosos no consolidados y con baja compactación estén saturados al momento del sismo o con un nivel freático muy cercano a la superficie. Las áreas de susceptibilidad alta de experimentar licuefacción corresponden a los suelos compuestos por sedimentos no consolidados, de baja a media compactación, constituidos por arenas gravillas y arenas con espesores de hasta $2 \mathrm{~m}$ que se caracterizan por tener un nivel freático somero, estimado entre 1 y $1,5 \mathrm{~m}$ de profundidad.

Las áreas de susceptibilidad media poseen capas de arena fina a media alternadas con grava y gravilla con espesores variables en las que se pueden encontrar capas turbosas de distinto espesor y profundidad variable y un nivel freático cercano a la superficie (1,5-2,5 $\mathrm{m}$ de profundidad).

Los terrenos de susceptibilidad baja son aquellos cuyos depósitos corresponden principalmente a gravas y con el nivel freático por debajo de $\operatorname{los} 2,5 \mathrm{~m}$ de profundidad.

Sin embargo, es de esperar que en la zona considerada de alta peligrosidad puedan existir 
algunos sitios particulares que posean un bajo peligro de licuación debido a la presencia de sectores con suelos densos o arcillosos.

La presencia de fallas activas durante el Holoceno al este y Pleistoceno al oeste del valle de Ullum-Zonda permite inferir que la licuación asociada al factor aceleración sísmica podría intensificarse en mayor medida en el sector oriental del área de estudio, en el caso de que el Sistema de falla Villicum-Zonda o las fallas Marquesado y Rinconada generen un evento sísmico.

Por otro lado, al norte y noreste de la Villa Ibáñez, se identificaron zonas de muy alta y alta susceptibilidad a la licuación respectivamente y al sur de la misma, zonas de alta a moderada susceptibilidad a la licuación. Los sectores urbanos correspondientes a las cabeceras departamentales de Villa Ibáñez y Villa Basilio Nievas se ubican en áreas con susceptibilidad alta a muy alta. También los sectores poblados, como Villa Tacú, ubicados al sur del embalse de Ullum y los clubes náuticos del área costera norte de dicho embalse se encuentran en las áreas más susceptibles de sufrir licuación. Por el contrario, los lugares menos susceptibles se corresponden con el sector proximal norte del abanico aluvial del río San Juan y el área con depósitos limo-arcillosos ubicada al norte de la quebrada de Zonda.

\section{Conclusiones}

El valle Ullum-Zonda en la provincia de San Juan, Argentina, se ubica en una zona sísmica, que en el pasado ha sido afectada por procesos de licuación de suelos y sedimentos gatillados por la actividad sísmica. En este trabajo se estudió la susceptibilidad a la licuación de los suelos y sedimentos del valle por medio de una metodología que consideró los principales factores que la condicionan, entre ellos: 1) Origen de depósitos sedimentarios, 2) Granulometría de suelos y sedimentos, 3) Posición del nivel freático, 4) Edad de los depósitos, 5) Magnitud/ distancia epicentral del evento sísmico gatillante, 6) Aceleración máxima registrada en el área y 7) Antecedentes históricos de licuación. El análisis y ponderación de estos factores permitieron construir un mapa de zonificación de la susceptibilidad a la licuación de los suelos y sedimentos del valle, al cual se vincula un índice que permite clasificar, cualitativamente, la susceptibilidad a la licuación como muy alta, alta, moderada y baja. Las zonas de mayor susceptibilidad a la licuación se ubican en el sector distal del abanico aluvial del río San Juan, las de alta a moderada susceptibilidad en su sector medio y las de moderada a baja susceptibilidad en el sector proximal-medio, y los principales factores condicionantes son la granulometría de los suelos y sedimentos y la profundidad del nivel freático.

La mayor parte de las zonas pobladas del valle de Ullum-Zonda se localizan en áreas catalogadas de alta a muy alta susceptibilidad a la licuación, esto debido principalmente a la baja profundidad del nivel freático. Tanto la villa cabecera del departamento Ullum (Villa Ibáñez) como la del departamento Zonda (Villa Basilio Nievas), además, los clubes náuticos ubicados en la periferia del embalse de Ullum y la Villa Tacú, situada al sur del mismo, se encuentran en el área más susceptible a sufrir licuación.

\section{Agradecimientos}

La presente contribución fue financiada con fondos del Programa Permanente del Gabinete de Neotectónica y Geomorfología del Instituto de Geología Emiliano P. Aparicio (INGEO) de la UNSJ. Las autoras agradecen a las revisoras S. Rebolledo y P. Ramírez y al editor W. Vivallo por sus sugerencias y comentarios que contribuyeron a mejorar este trabajo.

\section{Referencias}

Alvarado, P.; Beck, S. 2006. Source characterization of the San Juan, Argentina crustal earthquake of 15 January 1944 (Mw 7.0) and 11 June 1952 (Mw 6.8). Earth and Planetary Science Letters 243 (3-4): 615-631.

Amick, D.; Gelinas, R.; Maurath, G.; Cannon, R.; Mot, D.; Billington, C.; Kemppinch, H. 1990. Paleoliquefaction features along the Atlantic Seaboard, U.S. Nuclear Regulatory Commission Report NUREG/CR-5613: $146 \mathrm{p}$.

González de Vallejo, L.; Ferrer, M.; Ortuño, L.; Oteo, C. 2009. Ingeniería Geológica. Prentice Hall Pearson Educación ( $3^{\circ} \mathrm{Ed}$.): 750 p. Madrid.

Harrington, H. 1944. El sismo de San Juan del 15 de enero de 1944. Corporación para la Promoción del Intercambio S.A.: 79 p. Buenos Aires.

INPRES. 1993. La verdadera dimensión del problema sísmico en la provincia de San Juan. Instituto Nacional de Prevención Sísmica, Publicación Técnica 18: 46 p. San Juan.

Kramer, S.; Stewart, J. 2004. Geotechnical aspects of seismic hazards. In Earthquake engineering: from 
engineering seismology to performance-based engineering (Bozorgnia, Y.; Bertero, V.; editors). London. United Nations Environmental Program (2003). GEO Latin America and the Caribbean Environment Outlook: 143-178.

Obermeier, S. 1994. Using liquefaction-induced features for paleoseismic analysis. In Using ground failure features for paleoseismic analysis (Obermeier, S.; Jibson, W; editors). United States Geological Survey, Open-File Report 94-633: A1-A98.

Obermeier, S.F.; Jacobson, R.B.; Smoot, J.P.; Weems, R.F.; Gohn, G.S.; Monroe, J.E.; Powars, D.S. 1990. Earthquake-induced Liquefaction Features in the Coastal Setting of South Carolina and in the Fluvial Setting of the New Madrid Seismic Zone. United States Geological Survey, Professional Paper 1504: 44 p.

Obermeier, S.; Martin, J.R.; Frankel, T.; Munson, P.; Munson, C.; Pond, E. 1993. Liquefaction evidence for one or more strong Holocene earthquakes in the Wabash valley of southern Indiana and Illinois. United States Geological Survey, Professional Paper 1536: 27 p.

Palacios, S.B. 2015. Peligros geológicos asociados a sismos destructivos al norte del río San Juan, Provincia San Juan, Argentina. Tesis Doctoral (Inédito), Universidad Nacional de San Juan, Facultad de Ciencias Exactas, Físicas y Naturales: $220 \mathrm{p}$.

Palacios, S.; Perucca, L.; Pantano, A.; Lara, G. 2017. Propuesta metodológica para el análisis de la licuación de suelos asociada a sismos destructivos Pre andes Centrales, Argentina $\left(31^{\circ} 30^{\prime} \mathrm{S}\right.$ y $\left.68^{\circ} 25^{\prime} \mathrm{O}\right)$. Anuario do Instituto de Geociencias 40: 55-69.

Perucca, L.; Moreiras, S. 2006. Liquefaction phenomena associated with historical earthquakes in San Juan and Mendoza Provinces, Argentina. Quaternary International 158: 96-109. doi: 10.1016/j.quaint.2006.05.023.

Perucca, L.; Vargas, H. 2014. Neotectónica de la provincia de San Juan, centro-oeste de Argentina. Boletín de la Sociedad Geológica Mexicana 66: 291-304.

Perucca, L.; Pérez, M.; Navarro, C. 2006. Fenómenos de licuefacción asociados a terremotos históricos. $\mathrm{Su}$ análisis en la evaluación del peligro sísmico en la Argentina. Revista de la Asociación Geológica Argentina 61: 567-578.

Perucca, L.; Lara, G.; Vargas, N. 2012. Nueva evidencia de actividad tectónica cuaternaria en la depresión Zonda-Maradona, provincia de San Juan. Revista de la Asociación Geológica Argentina 69: 97-105.

Rocca, J.A. 1969. Geología de los Valles de Tulum y Ullum-Zonda, Provincia de San Juan. Plan de Agua Subterránea. Consejo Federal de Inversiones, Publicación P-31: 140 p. San Juan.

Rodríguez Pascua, M. 1997. Paleosismicidad en Emplazamientos Nucleares. Estudio en Relación con el Cálculo de Peligrosidad Sísmica. Consejo de Seguridad Nuclear, Colección Otros Documentos: 286 p. Madrid.

Salcedo, E.; Castro, T.; Massanés, E. 1976. Estudio de suelos y drenaje de los Valles de Ullum-Zonda. Instituto Nacional de Tecnología Agropecuaria, Estación Experimental Agronómica San Juan, Argentina, Publicación Técnica: $210 \mathrm{p}$.

Siame, L.L.; Bellier, O.; Sébrier, M.; Bourlès, D.L.; Leturmy, P.; Pérez, M.; Araujo, M. 2002. Seismic hazard reappraisal from combined structural geology, geomorphology and cosmic ray exposure dating analyses: The Eastern Precordillera thrust system (NW-Argentina). Geophysical Journal International 150: 241-260.

Tinsley, J.C.; Youd, T.L.; Perkins, D.M., Chen, H.T.F. 1985. Evaluating liquefaction potential. In Evaluating earthquake hazards in the Los Angeles region-An Earth-Science Perspective (Ziony, J.I.; editor). United States Geological Survey, Professional Paper 1360: 263-315.

UCSB NEES. 2018. The Wildlife Liquefaction Array http://nees.ucsb.edu/ (Última visita 25/07/2020).

USGS. 2018. US Geological Service, On-Line Catalogue http://neic.usgs.gov/neis/epic/epic_circ.html(Última visita 22/12/2018).

Youd, T.L; Steidl, J.H.; Nigbor, R.L. 2004. Lessons learned and need for instrumented liquefaction sites. Soil Dynamics and Earthquake Engineering 24: 639-646.

Manuscript received: March 23, 2020; revised/accepted: September 2, 2020; available online: January 29, 2021. 